\title{
Descrição de uma nova espécie de Balbagathis Quate (Diptera, Psychodidae) do Brasil
}

\author{
Freddy Bravo ${ }^{1}$
}

\begin{abstract}
'Departamento de Ciências Biológicas, Universidade Estadual de Feira de Santana. Av. Universitária s/n, 44031-460 Feira de Santana-BA, Brasil. Endereço eletrônico: fbravo@uefs.br.
\end{abstract}

\begin{abstract}
Description of a new species of Balbagathis Quate (Diptera, Psychodidae) from Brazil. Balbagathis intrincata sp. nov. is described from northeastern Brazil (Bahia). It is the first record of the genus in Brazil.

Keywords. Balbagathis intrincata; Brazil; new species; Neotropical; Psychodidae.

Resumo. Balbagathis intrincata sp. nov. é descrita do nordeste do Brasil (Bahia). Este é o primeiro registro do gênero no Brasil.

Palavras-Chave. Balbagathis intrincata; Brasil; espécie nova; Região Neotropical; Psychodidae.
\end{abstract}

O gênero Balbagathis Quate, 1996, foi criado, dentro da tribo Maruinini, para abrigar duas espécies da Costa Rica, com o primeiro flagelômero reduzido e globuloso: Balbagathis sylvatica Quate, 1996 e B. talamanca Quate, 1996 (QuATE 1996). Uma espécie nova de Balbagathis do Nordeste brasileiro é descrita neste trabalho.

O espécime foi coletado com armadilha luminosa tipo "Luiz de Queiroz" em uma área de mata úmida, restrita ao curso do rio Pancada Grande próxima à cachoeira com o mesmo nome do rio ( $\left.13^{\circ} 43^{\prime} \mathrm{S}-39^{\circ} 08^{\prime} \mathrm{W}\right)$. A área de coleta está inserida no Bioma Mata Atlântica, fazendo parte da região conhecida como baixo sul da Bahia. O exemplar estudado foi tratado com solução aquosa de hidróxido de potássio $(\mathrm{KOH})$, montado em lâmina permanente e depositado na Coleção Entomológica da Universidade Estadual de Feira de Santana (CUFS), Feira de Santana, Bahia.

\section{Balbagathis intrincata sp. nov.}

(Figs. 1-8)

Holótipo macho, BRASIL, Bahia, Ituberá, 01.VII.2003, Bravo, F. col. (CUFS).

Holótipo macho. Comprimento do corpo, desde o início do tórax até o final do abdome, 1,7 $\mathrm{mm}$. Cabeça subcircular, ponte ocular de três facetas de largura; margens da ponte ocular contíguas. Antena incompleta, escapo subcilíndrico (Fig. 1); pedicelo subesférico (Fig. 1); flagelômeros nodiformes (Figs. 1, 2, 3); primeiro flagelômero menor, subcilíndrico (Fig. 1); ascóides delgados, 1,5 vezes tão longos quanto o flagelômero, enrolados, um par por flagelômero (Fig. 3). Palpo maxilar com quatro artículos (Fig. 4); comprimento relativo dos palpômeros: 1.0:1,6:2,0:2,4. Asa (Fig. 5): sem cerdas na membrana alar, restritas apenas às veias; comprimento da asa $1,4 \mathrm{~mm}$; largura máxima $0,56 \mathrm{~mm} ; \mathrm{R}_{5}$ terminando no ápice; $\mathrm{Rs}$ pectinada (Fig. 5). Tergito 9, cercos, gonocoxito e gonóstilo com pilosidade (Figs. 6, 7, 8). Gonocoxito de formato cônico lateralmente, com quase a metade do comprimento do tergito 9 (Fig. 6). Gonóstilo digitiforme, com o ápice arredondado, quase do mesmo comprimento do apódema edeagal (Figs. 6, 7). Esternito 9 como uma estreita banda unindo os gonocoxitos (Fig. 7). Esternito 10 com ápice arredondado e micropilosidade apical na superfície dorsal (Fig. 8). Tergito 9 sub-retangular (Fig. 8). Cercos longos, digitiformes, duas vezes o comprimento do tergito 9 (Fig. 6); tenácula simples, subtriangular (Fig. 6). Presença de uma placa (= processo parabasal de QuATE 1996) acima do edeago, esclerotizada, contendo um par de expansões laterais (Fig. 7); expansão direita com formato diferente do da esquerda, sendo esta última mais larga no ápice (Fig. 7). Edeago estreito, digitiforme do mesmo comprimento que as expansões laterais do processo parabasal (Fig. 7). Parâmeros menores que o edeago; esquerdo subtriangular e direito com ápice bifurcado (Fig. 7). Apódema edeagal longo (Figs. 6, 7), estreito na base e largo no ápice (Fig. 7). Apódema gonocoxal quase a metade do comprimento do apódema edeagal (Fig. 6).

Comentários. Balbagathis intrincata sp. nov. é a primeira espécie do gênero descrita para o Brasil. O gênero Balbagathis, conhecido apenas da Região Neotropical, é reconhecido pela presença da Rs radial e pelo tamanho reduzido do flagelômero 1. Até agora, eram conhecidas apenas duas espécies, ambas da Costa Rica, sendo que de $B$. sylvatica foi descrita apenas a fêmea e de B. talamanca o macho (Quate 1996). Duas características de $B$. intrincata $\mathbf{s p . ~ n o v . , ~ o ~ a s c o ́ i d e ~} 1,5$ vezes o comprimento do flagelômero e $\mathrm{a}_{2}$ não unida à $\mathrm{M}_{1}$, permitem diferenciá-la de $B$. sylvatica, espécie que possui um ascóide mais de duas vezes o comprimento do flagelômero, $\mathrm{e}_{1}$ unida à $\mathrm{M}_{2}$. A terminália masculina de $B$. intrincata $\mathbf{s p . ~ n o v . ~ d i f e r e ~ d a ~}$ terminália masculina de $B$. talamanca por apresentar expansões do processo parabasal não digitiformes como em $B$. talamanca. Além disso, os parâmeros da espécie nova são diferentes dos 



Figs. 1-8. Balbagathis intrincata $\mathbf{s p . ~ n o v . ~ 1 , ~ e s c a p o , ~ p e d i c e l o ~ e ~ t r e ̂ s ~ p r i m e i r o s ~ f l a g e l o ̂ m e r o s ; ~ 2 , ~ f l a g e l o ̂ m e r o s ~} 8$ e 9; 3, flagelômero 7; 4, palpo maxilar; 5, asa direita; $\mathbf{6}$, terminália masculina, vista lateral; $\mathbf{7}$, terminália masculina, vista dorsal; $\mathbf{8}$, terminália masculina, vista ventral; aped = apódema edeagal; apgx = apódema gonocoxal; ed = edeago; $\exp =$ expansão do processo parabasal; gs = gonóstilo; E9 = esternito 9; ppb = processo parabasal; pr = parâmero.

de $B$. talamanca, sendo que o direito é largo no ápice e bifurcado, enquanto que na espécie da Costa Rica, termina em ponta. Outra diferença entre estas duas últimas espécies é o formato do apódema edeagal, que na espécie nova tem o formato de uma raquete de tênis enquanto que em $B$. talamanca é subtriangular.

Etimologia. O nome da espécie é alusivo ao formato complexo da genitália masculina.

\section{REFERÊNCIA}

Quate, L. W. 1996. Preliminary taxonomy of Costa Rican Psychodidae (Diptera), exclusive of Phlebotominae. Revista de Biologia Tropical 44 (Supplement 1):1-81. 